\title{
XX. Observations on Malaria, with suggestions for ascertaining its nature: read before the Literary and Philosophical Society of Manchester, November 15, 1838
}

\section{Thomas Hopkins Esq.}

To cite this article: Thomas Hopkins Esq. (1839) XX. Observations on Malaria, with suggestions for ascertaining its nature: read before the Literary and Philosophical Society of Manchester, November 15, 1838, Philosophical Magazine Series 3, 14:86, 104-121, DOI: $10.1080 / 14786443908649680$

To link to this article: http://dx.doi.org/10.1080/14786443908649680

$$
\text { 曲 Published online: } 20 \text { Aug } 2009 .
$$

Submit your article to this journal ए

$$
\text { ЦIl Article views: } 2
$$

Q View related articles ¿ 
tensity. It is easier to accustom a plant of the lowlands to this elevation than to bring down those of the paramtos. Thus the orange and lemon trees, Aguacates (Laurus persen) Ricinus communis, Datura arborea, all natives of the hot lowlands, grow and flourish, more or less, at an elevation of 8000 feet above the level of the sea.

[To be continued.]

XX. Observations on Malaria, with Suggestions for ascertaining its Nature: read before the Literary and Philosophical Society of Manchester, November 15, 1838. By Thomas Hopkins, Esq.*

MALARIA is considered the scourge of a considerable portion of Italy, where it is spoken of with an undefinable feeling of horror. It is not, as its name may seem to imply, supposed to be simply bad air, but a poisonous effluvium arising from some undiscovered operation of nature, and known only through its dreadful effects on human beings. The volcanic nature of the country, the gases thrown from its surface by the agency of internal heat, with their offensive smells, are in the innagination of the people connected with the cause of marsh fever, and designated by the word Malaria. The author of the description of Latium speaks of the volcanic soil being prejudicial to the atmosphere; and Mrs. Starke, in her account of Rome, talks of the sulphur, arsenic and vitriol which abound, producing malaria. This lady may be considered as speaking the ordinary language of the people of the country on the subject. Learned writers too have treated of malaria in a way almost equally mysterions, among whom may be named Dr. Macculloch. The Doctor does not indeed suppose that sulphur or vitriol is instrumental in producing the poison, but that it is the product of vege.. table fermentation or putrefaction, the form and mode of operation of which we are not able to trace, becoming conscious of its existence only by witnessing its effects. The pest is shown to be worse in Italy than in other parts of Europe, but the Doctor has shown that it really prevails in other countries, and to a greater extent than had been previously suspected. Whatever may be the peculiar nature of malaria, Dr. Macculloch seems satisfied that it does not arise from the presence of minerals, nor from local causes confined

* Communicated by the Author. The reader may advantageously compare this paper with Mr. Addison's "Remarks on the Influence of Terrestrial Radiation in determining the site of Malaria," Phil. Mag. and Annals, N.S., vol. iv. p. 272, et seq.-EDIT. 
to any particular country. It is indeed distributed extensively over the surface of the earth. Asia, Africa, and America feel the scourge in a more violent degree than it is felt in any part of Europe: the plains of Bengal, the vallies of the African const, and the West Indian islands are infected in a more deadly degree than even Italy; it is therefore reasonable to infer that the locality of gases or minerals is not connected with its production. It is found too in climates having different temperatures to those of the countries just named, as on the eastern coast of England, in France, and Holland: very high temperature therefore does not seem essential to its production. But though not absolutely requisite to its production, high temperature appears to increase its virulence, the injurions effects on the human constitution having a palpable relation to the temperature of the atmosphere. Thus in Lincolnshire, France, and Holland, its operation is slow, and it requires considerable time to produce fatal effects; but in the Campagna of Rome, it is said that a single night passed within the full influence of the pest endangers life. In the jungles of Bengal it is fully as bad as in the Campagna, and in the vallies of the western coast of Africa the greater number of the crew of a ship have been known to die in a short time. Thus it becomes apparent that the virulence of the fever arising from malaria is great in proportion to the heat of the climate.

Yet great heat alone does not seem capable of producing the poison. However high the temperature may be, provided it is not accompanied by moisture, the air is found to be healthy. The plains of Russia are hotter in summer than the marshes of Holland, but no malaria is found in the former, while it abounds in the latter, because the plains of Russia are dry as well as hot. Rome is only seven degrees hotter than Moscow in the hottest month of the year, yet malaria is virulent in the one, while it does not exist in the other. In the sandy deserts of Asia and Africa we have perhaps the hottest climates of the globe, but as these deserts are at the same time dry malaria is not prevalent in them. The inference is that heat alone will not produce malaria, but that the presence of moisture also is necessary.

Dr. Macculloch admits, " that the extreme of evil fiom malaria occurs in tropical climates, it appearing almost proportioned to the heat of the climate, and, what is important to observe, to the moisture also." $\mathrm{He}$ also remarks that "Egypt is free from the fever arising from malaria except at the period of the subsidence of the Nile, unless where, as at Damietta, the cultivation of rice is pursued." But the Doctor 
afterwards attempts to show that heat and moisture are merely agents in the production and distribution of a poisonous exhalation from vegetable matter, which exhalation he says is the true malaria. A moist air, says he, " is the best conductor of the malaria, as moisture in the air, under the form of evening mists or in other modes, appears to be even its proper vehicle or residence." And again he says, "water in some form is necessary to the production of that peculiar. vegetable decomposition which is the source of this poison; and the action of moisture is twofold, inasmuch as it not only accelerates vegetable decomposition, but renders the atmosphere a fitter conductor of the poison." It is not here pretended that this poison which is stated to be the result of vegetable decomposition has ever been detected in a palpable form. It is not asserted that its existence as a peculiar substance has been ascertained. It is only from effects produced on human health that its existence is inferred. Moisture, says the Doctor, is not capable of poisoning the atmosphere; and as he finds that the atmosphere is poisoned, he infers that the poison is exhaled in the decomposition of vegetable substances.

There is a prevalent belief in many parts of the world that fogs coming from the sea produce fevers of the same kind as the malaria fever: this belief is evidently at variance with the theory espoused by Dr. Macculloch, and he thus reasons with those who entertain it. "'The proof that it is malaria in the fog, and not the fog itself which is the cause of disease, is evinced by the following facts: No intermittents are ever produced on the western or northern shores of the island, and for the plain reason that there is no land whence they may arrive. The clouds of mountainous regions do not produce fevers though these are also fogs; and what forms a most absolute proof of this is, that in Flanders it is the fogs which come with a south-west wind or the southerly winds which transport and propagate malaria and diseases, while as soon as the winds shift and blow from the sea the fevers disappear, though these particular winds are so charged with fog as to darken the whole country for days." These are the facts on which the Doctor relies, and he remarks, that "it ought surely to be unnecessary to say that if fogs alone could produce such fever water itself must be the poison, since a fog is a cloud, and its constituents when pure are only atmospheric air and water."

With respect to the first alleged fact, that no intermittents are produced on the western or northern shores of our island, the reason for it may be found in the circumstances of these 
shores being either rocky, or well drained and under cultivation, and consequently dry. They are also nearer to the Atlantic Ocean, and therefore cooler in the summer than the eastern coast. These two causes may be sufficient to account for the difference which is found on the eastern and western coasts of this country. But I have been informed by Dr. Briggs of Ambleside, formerly resident in Liverpool, that in his younger days autumnal agues were common on the low grounds of Lancashire, particularly in that part called the Fylde country, and that they occasionally prevail at present. Their diminution may be attributed to the better clrainage of the country, which has converted it from a comparative marsh to dry tillage land. That the clouds of mountainous regions do not produce fevers may arise from their low temperature. And as to the fact that south-west and south winds produce fevers in Flanders, while on a sea wind coming which covers the country with fogs the fevers disappear, this may only prove that the sea wind being a cold one, the reduction of the temperature caused the fever to cease. The Doctor seems to think that there is great force in the remark " that if a fog alone could produce fever water itself must be the poison:" but the argument may not, as we shall presently see, turn on the water in the atmosphere as water, but as steam or elastic vapour. And it may be found that when there is a certain quantity of steam in the atmosphere at a high temperature, disease may be a consequence, notwithstanding that water is wholesome in a liquid state. Dr. Macculloch's opinions respecting the cause of malaria are at variance with numerous and well ascertained facts. This pest is found on sea borders and islands, as on the coasts of Italy and Africa, on the small Maldive islands in the Indian Ocean, in the West Indian islands, even in Barbadoes, which pushes out east a considerable way into the Atlantic; it is also found at sea at great distances from land, and beyond the reach of effluvia from vegetable putrefaction. In the valuable statistical report of sickness and mortality among the troops in the West Indies, recently laid before the House of Commons, it is said, when speaking of the hypothesis of vegetable exhalation producing malaria,- "Were this hypothesis correct, we might expect that British Guiana would, from its proximity to this canse of disease, be most subject to its operation, and consequently the most unhealthy, and that the colonies further to the north, being least exposed to it, would enjoy the greatest degree of salubrity. The result of our investigations into the comparative mortality in each colony shows however that their relative salubrity is by no means 
affected by their proximity to, or distance from, the continent." (See table of relative mortality at the end.)

The atmosphere in which we live, it is well known, has within it azotic gas, oxygen, a small portion of carbonic acid gas, and invisible vapour of water, or steam. The nature of the three first-named substances, as far as respects their influence on animal life and health, is tolerably well known; but the same cannot, I believe, be said of the steam which exists in the atmosphere; nor am I aware that any scientific attempt has been made to trace its influence on the animal œconomy with relation to health and disease. It is known that too dry an atmosphere is productive of unpleasant and sometimes of very painful consequences. Evaporation from the body goes on so freely as to deprive it in too great a degree of moisture and to produce a constant thirst. A certain degree of moisture in the air keeps the body soft and gives that clearness of complexion common in many parts of the north-west of Europe, which is supposed to indicate vigorous health. But in other parts of the world there is, with reference to the animal oconomy, a superabundance of steam in the atmosphere. This is popularly recognised in those parts when it takes the form of dampness, as it is then thought to be injurious to health; but it has not been treated of scientifically. In the absence of any treatise on the subject I propose to call attention to a few points, in the hope that it may induce others to institute a full inquiry, meteorological, chemical and physiological, such as the important nature of the subject demands.

Let us imagine that at some certain time no vapour existed in the atmosphere: according to the known laws of evaporation vaponr would immediately begin to arise from all wet surfaces; and supposing evaporation to proceed, the whole of the space occupied by the atmosphere would soon be filled with vapour, or invisible steam ; the quantity being proportioned to the temperature of each particular place. Where the temperature was low there would be but little steam, where it was high there would be more, and every part would in time have its maximum quantity, when of course no more could rise. In this state, as there would be no condensation of vapour, there would be no clouds and no rain. But owing to the unequal influence of the sun on different parts of the earth's surface, and the diurnal motion of the globe, this state of things does not exist. Between the tropics the sun vaporises water freely, and at the same time by its heat rarefies the air. The vapour ascends with the rarefied air to the upper regions of the atmosphere, cold air flows in below 
from parts nearer to the poles, and the process is repeated and continued. The vapour that is taken up with the rarefied air flows with it through the higher region towards the poles, and becoming cooled in its passage, a portion of the vapour is deposited in the form of rain. The air thus cooled and deprived of part of its vapour returns from each polar region, flowing along the surface of the earth, and has its temperature increased by the sun's heat as it advances towards the equator; it consequently becomes a dry air, or is disposed to take up vapour from moist surfaces. Thus we see that in accordance with the general laws of nature, the air near to the surface of the earth which is flowing from the poles to the equator is a dry air.

But through the influence of local causes this course of nature, though general, is not universal. While in some parts the air near the surface of the earth is very dry, in other parts it is so fully charged with moisture as to prevent further evaporation taking place at the existing temperature. In this case, the dew-point, being that degree of the thermometer at which dew is formed from the atmosphere, is the same as the temperature. In different parts of the world there are various degrees of dryness in the atmosphere, and these are expressed by the relation which the dew-point bears to the temperature. When the dew-point is only one degree below the temperature evaporation goes on very feebly; when more than one, it proceeds more vigorously; when at ten, fifteen, or twenty degrees below the temperature, evaporation goes on with proportionally increased energy. Dr. Dalton made various observations on the subject near to and on the mountain of Helvellyn in Cumberland. He found that at one time, in the valley below the mountain, the temperature was $70^{\circ}$, the dewpoint $53^{\circ}$, difference $17^{\circ}$; at another time the temperature was $56^{\circ}$, the dew-point $46^{\circ}$, difference $10^{\circ}$ : of course the energy of evaporation would in each case be proportioned to the difference. At the same time, on the mountain, 855 yards above the valley, the temperature was the first time $56^{\circ}$, dew-point $46^{\circ}$, difference $10^{\circ}$. The second time it was $46^{\circ}$, dew-point $42^{\circ}$, difference $4^{\circ}$.

Thus in these four observations the energy of evaporation would be as the numbers of the difference, or as $17,10,9$, and 4. In the same paper in which the above facts are to be found, published in the 4th volume of the Society's 'Transactions (Manchester) the Doctor has given a table of numbers exhibiting the drying power of the atmosphere, which is one form of expressing the energy. of evaporation.

Dr. Dalton also states that in twenty years of observation 
chiefly at Manchester, he found that in the months of June, July, and August the dew-point generally ranged from $50^{\circ}$ to $60^{\circ}$; that it was only once at $64^{\circ}$, once at $63^{\circ}$, five times at $62^{\circ}$, three times at $61^{\circ}$, and twenty times at $60^{\circ}$. But in other parts of the world where malaria prevails, different meteorological facts present themselves, and furnish ground for presuming that the laws of evaporation affect the people of those countries differently to what they do the inhabitants of our colder climate. In Rome, in the hottest month of the year, during the day the temperature ranges from $90^{\circ}$ to $100^{\circ}$ in the shade, and the air is damp; the dew-point must therefore be high.

In Captain Alexander's observations on the western coast of Africa, we are told that "four days after leaving Teneriffe, while proceeding for the river Gambia, on the 6th of October, the wind at south-east swept over the ocean charged with moisture. At noon the thermometer under the awning was at $80^{\circ}$, while with Daniell's hygrometer I found the dew-point at $70^{\circ}$. On the 7th of October during a sirocco the thermometer was at $86^{\circ}$, the hygrometer $76^{\circ}$. At the end of November in the Bight of Benin, in sight of the island of St. Thomas, the temperature was $84^{\circ}$, the hygrometer $79^{\circ} ! "$ In the meteorological register kept by $\mathrm{Mr}$. Oldfield, surgeon in Laird and Oldfield's expedition up the Niger, we find it stated that during the month of April, on the river, the temperature was generally above $100^{\circ}$, and on the 14th of April it reached $118^{\circ}$. No hygrometrical return is given, but as the air is stated to have been damp, it may safely be inferred that the dew-point was extremely high.

Here then we have instances where the dew-point was in different places at the respective heights of $42^{\circ}, 46^{\circ}, 53^{\circ}, 60^{\circ}$, $70^{\circ}, 76^{\circ}$, and $79^{\circ}$, and from Oldfield's register it may be presumed to have been much higher on the Niger, probably $90^{\circ}$. Suppose water of the temperature of $98^{\circ}$ to be placed in these various atmospheres, and it will be seen that the energy of evaporation of this water would be very different in those different places. Evaporation would go on much more freely when the dew-point was at $42^{\circ}$ than when at $60^{\circ}$, at $60^{\circ}$ than when it was at $70^{\circ}$, at $70^{\circ}$ than $76^{\circ}$ or $79^{\circ}$; and the nearer the dew-point approached to $98^{\circ}$, the temperature of the water, the more feeble would be the evaporation. Now the temperature of the human body in its healthy state being $98^{\circ}$, when this body is placed in an atmosphere the dew-point of which is $42^{\circ}$ or even $60^{\circ}$, evaporation will go on vigorously. Let the dew-point rise to $70^{\circ}$, and still evaporation might possibly go on with considerable energy; but should the dew-point 
be raised to $80^{\circ}$ or $90^{\circ}$, evaporation from the body must become very feeble.

In a paper read March 1830, and printed in the 5 th vol. of the Society's Transactions, Dr. Dalton has shown that a healthy man taking daily into his stomach 53 ounces of fluid gives off' from the external skin in the same time $6 \frac{3}{4}$ ounces of water, and from the lungs $20 \frac{1}{2}$ ounces, making together $27 \frac{1}{4}$ ounces. Now is it not clear that this important process in the animal œconomy must be variously affected by the hygrometrical state of the atmosphere; differently when the dewpoint is at $50^{\circ}$ to what it will be when at $60^{\circ}, 70^{\circ}, 80^{\circ}$, or $90^{\circ}$ ? Were the dew-point to be carried up to $98^{\circ}$, this process, it would appear, must stop, evaporation would cease, and the $27 \frac{1}{4}$ ounces of water would remain in the system, or be disposed of by nature in some different mode, which would constitute a material derangement of the animal ceconomy. Again, it requires a considerable portion of caloric to vaporise $27 \frac{1}{4}$ ounces of water; and when this quantity of water is daily thrown off by evaporation, it is presumed that the requisite quantity of caloric is abstracted from the human body. Evaporation seems indeed to be the agent that nature employs to regulate the temperature of the body, and when it is stopped or materially impeded fever generally ensues, the temperature of the body rises, and from $98^{\circ}$ goes up at last to fever heat or $112^{\circ}$. Lavoisier and Seguin estimated the average loss by perspiration from the skin and lungs in twenty-four hours at 2 pounds 13 ounces, of which I pound 14 ounces were dissipated by the skin, and 15 ounces by the lungs. (Traité Elémentaire de Chimie, $3^{\text {me }}$ édition, 228.) The degree of dryness of the atmosphere may, it is obvious, influence the whole quantity evaporated, and also the proportions given off respectively by the external skin and lungs.

Malaria seems not to prevail in a virulent state where the dew-point is below $60^{\circ}$. In Lincolnshire and parts of Holland and of France the dew-point is probably sometimes above that height towards the end of the summer: in those countries malaria fever prevails in its mildest form, but always at those periods when the dew-point is presumed to be the highest. In the maremma of Tuscany, the Campagna of Rome, and other parts of the south-west coast of Italy, in the latter part of the summer the dew-point must be high, and precisely at this period of the year in these places malaria prevails, and in the worst form in the hottest and dampest parts. In the West Indies, in Bengal, and in the African valleys the same facts are observable; malaria is always viru- 
lent in proportion to the height of the dew-point. It is however greatly to be lamented that we have not more particular and full hygrometrical returns of the state of the atmosphere in those parts of the world; were we furnished with such returns, there is little reason to doubt that it would be easy to show, by the evidence of facts, that there is such a general coincidence of a high dew-point and the prevalence of malaria fever as would place them in the relation of cause and effect. In the returns from the West Indies, published in the Statistical Report of the mortality there, we have a monthly hygrometrical return for the year 1832, from the island of St. Vincent : it is the only one in the whole report, and the substance of it is given at the end. It will be seen from this that the mean of the dew-point for the year is $68^{\circ} .86$; the lowest, in the month of February being $67^{\circ} \cdot 14$, and the highest, in July, $70^{\circ} \cdot 25$.

From the laws of evaporation as ascertained by experience, it is known that the rest or motion of the air has considerable influence on evaporation from wet surfaces. When vapour rises from these surfaces it remains for some time resting upon and near to them, where it checks further evaporation. But when a current of air by its mechanical action carries away the newly formed vapour, fiesh vapour immediately escapes, and the process is repeated : the influence of winds in drying is a familiar instance of this fact. The hurnan body is disposed to give out vapour to a given extent to an atmosphere, the dewpoint of which is, say $70^{\circ}$; but without motion in the air the vapour first given out would impede further evaporation; a wind removes this impediment and suffers the evaporation to go on more freely. In accordance with this it is known that malaria fevers more commonly prevail in a warm damp atmosphere when it is stagnant! $\dot{A}$ brisk wind is said popularly to purify the air, and to take away mephitic vapours; may it not merely facilitate evaporation? Persons suffering under malaria fevers are relieved by fanning! Were the air charged with poisonous vegetable niasmata, it would be reasonable to conclude, that fanning, by bringing more of this poisoned air into contact with the patient, would increase the disorder! But if the view here taken be correct, the cause of the relief that is felt becomes sufficiently obvious; the evaporation which was checked by the previous accumulation of vapour is accelerated by its removal.

In temperate climates the heat of the atmosphere is considerably below that of the human body, and the dew-point is ordinarily below the temperature of the atmosphere. But with reference to perspiration it seems to be as important that 
the dew-point should be below the temperature of the atmosphere, as that the temperature of the atmosphere should be below that of the human body, unless the temperature be very low. The temperature and dew-point being the same, and at $60^{\circ}$, evaporation would not proceed rapidly from the human body in a stagnant atmosphere. But if a much colder atmosphere, say $40^{\circ}$, were to be fully saturated, the body being $98^{\circ}$, would warm the air immediately around itself, give it a capacity to take up more steam, and at the same time create a more decided upward current that would continually change that part of the air which was in immediate contact with the body.

Writers and travellers when speaking of a damp atmosphere commonly restrict their remarks to those atmospheres which discharge rain, or are charged with fogs, their object being generally to intimate that such atmospheres wet or moisten substances exposed to them. But an atmosphere may be saturated with steam, without giving out any part of it to substances immersed in it which are of an equally high temperature. Suppose both the temperature and the lew-point to be $70^{\circ}$ during the night, neither rain would fall nor dew be formed, and yet with reference to evaporation it would be a damp atmosphere, seeing that no evaporation could take place in it from water of the same temperature. It is the existence of transparent elastic steam in certain quantities in the atmosphere which prevents further evaporation from wet surfaces, and it is this steam we have now under consideration, and not either the fall of rain or the floating of condensed vapour. These are effects of this elastic steam having previously existed; but it is the stean itself of which we are now treating, and of its effects in checking evaporation. An atmosphere of the temperature of $118^{\circ}$, as found by Oldfield in Africa, might possibly have a dew-point of $98^{\circ}$, and would consequently have a drying power of 20 degrees, but the transparent elastic steam in this atmosphere would put an entire stop to evaporation from the human body, seeing that the temperature of that body in a healthy state does not rise higher than $98^{\circ}$. It is therefore necessary to observe that it is neither the rain that falls, nor the condensed vapour that floats in damp climates where malaria prevails, that is here supposed to constitute that malaria, but solely the quantity of invisible steam which, by its mechanical pressure on the surface of the skin and lungs, prevents the ordinary process of healthful evaporation from being continued, and thus this invisible steam becomes the real malaria. When this steam stops evaporation from the body, the $27 \frac{1}{4}$ ounces of water previously

Phil. Mag. S. 3. Vol. 14. No.86. Feb. 1839. I 
thrown off by evaporation remains in the body, with the heat requisite to evaporate it, and this may cause fever, and carry the temperature of the body up to $112^{\circ}$.

'The evidence of what is called dampness of the atmosphere, as given by writers generally, is of a loose and unsatisfactory nature. Even in the valuable report from the West Indies already alluded to, the intelligent compiler says: "If the mortality of the troops depended materially on the influence of moisture, we might expect it to attain its maximum in those stations where the greatest fall of rain takes place, whereas the average mortality of troops in Jamaica is at least double that which prevails among those in British Guiana, though the quantity of rain which falls in that island is little more than one half as great as in Guiana."

Here we see that the quantity of rain that falls is taken as evidence of the moisture of the climate, whereas it is quite possible that rain may fall from a considerable elevation while the dew-point is comparatively low near the surface of the earth, while on the other hand the dew-point may be very high without much rain falling. When the autumnal rains fall at Rome malaria is diminished, but those rains by cooling the country lower the dew-point or reduce the quantity of steam in the air. In the summer in Great Britain the dewpoint is at times 15 or 20 degrees below the temperature when clouds are forming and rain falling from a considerable elevation. The fall of rain is evidently not an indicator of the state of the dew-point near the surface of the earth.

In directing our attention to this subject it may be worth while to observe, that it is not so much the mean temperature of certain places that should be noticed, as the high temperature of the days vaporising much water, and thus raising the dew-point very high. A temperature of $100^{\circ}$ in the day and $60^{\circ}$ at night, making a mean of $80^{\circ}$, might in a marshy country, such as that near Rome, give a dew-point of, say $90^{\circ}$, at or near sunset, while a uniform temperature of the mean $80^{\circ}$ could not possibly give a dew-point of $90^{\circ}$, nor above $80^{\circ}$. A day temperature of $70^{\circ}$ and a night temperature of $40^{\circ}$, making a mean of $55^{\circ}$, might give a dew-point of $60^{\circ}$, but a uniform temperature of the mean could not give so high a dew-point as $60^{\circ}$. As the former may be taken to represent the Campagna of Rome, the latter may be considered to represent the marshes of Lincolnshire. Now when on the going down of the sun the temperature of the Campagna sunk to $90^{\circ}$, the temperature and the dew-point might be the same; and when in Lincolnshire the temperature sunk from $70^{\circ}$ to $60^{\circ}$, the temperature and dew-point might also be 
the same. But the dew-point the same as the temperature even at $60^{\circ}$, with a stagnant atmosphere, might seriously check evaporation from the human body, though not to the same dangerous extent as the higher dew-point in the Campagna of Rome.

Captain Cook and others experienced the unhealthy influence of hot and damp air at sea, far removed from the supposed seats of poisonous effluvia from decaying vegetable substances, and also found the benefit of heating and drying the air. In Cook's Voyage from 1772 to 1775, p. 9, it is stated that, " in latitude $3^{\circ}$ north, August 20 to 27 th, the thermometer generally at noon kept from $79^{\circ}$ to $82^{\circ}$. On the 27 th spake with Captain Furneaux, who informed us that one of his petty officers had died. At this time we had not one sick on board, though we had everything of the kind to fear from the rain we had had, which is a great promoter of sickness in hot climates. To prevent this I took every necessary precaution by airing and drying the ship with fires made between decks, smoking, \&c. \&c.; neglect of these seldom fails to bring on sickness, but more especially in hot and wet weather." And in page 291, vol. ii. "Care was taken to keep the ship clean and dry between decks. Once or twice a-week she was aired with fires. I had also frequently a fire made in an iron pot at the bottom of the well, which was of great use in purifying the air in the lower part of the ship." Sir J. Pringle in his account of Cook's sanatory precautions, says, that "some old ships were more healthy than the new ones, because the former having their galley in the forepart of the orlop, the chimney vented so ill, that it was sure to fill every part with smoke. This was a nuisance for the time, but, as he thought, abundantly compensated by the extraordinary good health of the crews." Perouse, when proceeding from the northern part of the Pacific to the Equator, and in the latitude of $10^{\circ}$ north, writes thus: "The heat was suffocating and the hygrometer had never indicated more humidity since our departure from Europe. We were breathing an air destitute of elasticity! which joined to unwholesome aliments diminished our strength, and would have rendered us almost incapable of exertion if circumstances had required it. I redoubled my care to preserve the health of the crew during this crisis produced by too sudden a passage from cold to heat and moisture. I ordered the ship to be dried and ventilated between decks." A high dew-point, no doubt, was here the cause of the illness, and the drying was merely heating the air so as to carry the temperature much above the dew-point. On the 20th of January the brothers Lander sailed in the 
ship Carnarvon from the island of Fernando Po, having " a crew of seven European seamen, two free negroes, one Krooman, one captain and two mates. Two of the seamen were ill of fever, Owen Williams and C. Hall. On Sunday, January 23, one of the sick seamen died. On January 26, three of the healthy men, namely, the steward, the second mate and a seaman, were taken ill of fever. January $27 \mathrm{th}$, a seaman taken ill of fever. The weather calm, with light winds; the island still in sight! Jannary 90 , another seaman taken ill of fever. The steward died. February 4, the captain taken ill. John Williams died. February 6, the chief mate taken ill of fever. February 7, Smith, seaman, died." Here there was doubtless a high dew-point, and the temperature was not, as in the instances of Cook and Perouse, raised much above it by fires. It would be very easy to give ample additional evidence of the pernicious effects of damp air at sea far beyond the influence of vegetable effluvia.

But it may be thought that, if warm and damp air is sufficient to produce fevers, the sea between the tropics would be found more unhealthy than the land, which is known to be contrary to experience. To this it may be replied that the ordinary cool current of air that flows from the poles to the equator is in general sufficiently dry even over the sea to prevent that part from being very unhealthy, or at least as much so as the hot and moist valleys between the tropics. Captain Basil Hall in his fragments of voyages says: "As we approached the equator the thermometer fell from $82^{\circ}$ in the day to $79^{\circ}$ or $80^{\circ}$ at night. The symptoms of change of climate became daily more manifest. Every skylight and sternwindow was fastened wide open, and every cabin scuttle driven out that a free draught of air might sweep through the ship. The seamen and marines dined on the main deck that the lower deck might be kept as cool and as airy as possible against the sultry and feverish night season. We generally exposed a dozen buckets full of sea-water on the gangway at 8 or 9 o'clock in the evening, and these being allowed to stand till the morning, 4 or 5 o'clock, became so much cooler than the sea by the evaporation during the night, that the shock was unspeakably grateful."

Here we perceive that evaporation was going on actively on the surfaces of the water in the buckets, the dew-point must therefore have been considerably below the temperature; yet even here we find the night season described as sultry and feverish, though the temperature was then a few degrees lower than it was during the day: this could arise only from the dew-point being then a little nearer to the tem- 
perature. But still the dew-point in Captain Hall's ship must evidentiy have been much below what it was in the Carnarvon. The above account of Captain Hall furnishes an instance of what has been already stated in a general form, that the heat of the sun rarefies the air, and makes it flow over high in the atmosphere, before it becomes fully saturated with vapour. The most important exceptions to this general law are to be found in those places where malaria most abounds, that is in heated valleys or marshes near to, or within the tropics. The sea at its surface, between the tropics, is seldom found much hotter than $80^{\circ}$; but we have seen that in African valleys the temperature has been from $100^{\circ}$ to $118^{\circ}$, and it follows that the latter places are likely to have a much higher dew-point than the former. In some of the African rivers, commanders on losing many of their men and having others ill of fever, have put out to sea in order to get out of reach of the poisonous influence; this however it is clear, from what has been said, may have been only a case where an atmosphere of, say $100^{\circ}$, highly charged with steam, was exchanged for one of $80^{\circ}$, with a dew-point of perhaps only $70^{\circ}$ or $65^{\circ}$. The superabundance of stean from heated valleys or flat coasts may however, it is obvious, be taken far out to sea by gentle winds, and thus parts over the sea may be made as unhealthy as hot and damp valleys. This may have been the case with the Carnarvon on board of which were the Landers. But so little attention has been paid to hygrometry by navigators, as to leave us in ignorance of what the dewpoints really were.

There seems good reason to believe that a warm and moist air may be rendered more healthful by heating it, because then the temperature would be so much higher than the dewpoint as to render it a drying air. But it is still more certain that a reduction of the dew-point much below the temperature removes the cause of malaria fevers: "The Harmattan," says Lander, "a land wind, passes over the sands of Africa, and while it lasts the dryness of the atmosphere produces an unpleasant feeling, but it is said to be not injurious to health." And again, "The effects of the Harmattan after the rainy season are most beneficial in drying up the vapours with which the atmosphere is loaded; and it has been observed, that on the return of this wind at the end of the rainy season, the recovery of invalids commences." But this dry wind seldom continues longer than three or four days. What the state of the dew-point is while it lasts I have never learned, but it must be very low compared with the temperature, as it dries the country with extraordinary rapidity. 
That malaria fever is an effect of an excess of steam in the atmosphere, more especially when the temperature is not considerably above the dew-point, may be inferred from various observed circumstances. In the neighbourhood of Rome, as soon as the morning sun hasraised the temperature, danger from malaria is much reduced. On the 10th of August the stubble and weeds of the Campagna are begun to be burnt, and it is found that whenever the heat from these fires raises the temperature, the air is for the time partially purified; doubtless because this heat, like that of the sun in the morning, dries the air as well as heats it; that is, raises the temperature to a greater height above the dew-point. It is a common remark in the Campagna, that keeping up a fire in a house during the night purifies the air; and it is well known that in those parts of Rome where the poor people are crowded together there is no malaria, while the thinly inhabited parts are affected. In order to avoid malaria, the wealthy Italians are careful not to sleep on a ground floor. And any one who has observed the way in which a fog rising from a neighbouring marsh or lake creeps along and spreads itself over the lower levels, even when the air appears to be still, will see why rooms of ground floors should be filled with damp air in certain places. The ancient inhabitants of Italy, as may be seen at Pompeii, built their houses round an interior square, the entrance to which could be easily closed; this enabled them effectually to keep out a low stratum of damp air. The streams of fog creeping along the ground as they do, enable us to account also for the local attacks of malaria. A slight current of air confined or turned by a valley, a ridge, a wall, or even a hedge, may take the vapour to a particular part, while other parts, at a small distance, may not be visited by it. The supply being continued from the source, the vapour may be sufficiently dense in certain parts to make those parts unhealthy; but when it expands and by its elastic force diffuses itself, it becomes too thin to saturate the adjoining air up to an unhealthy degree. The same kind of observation will apply to planting woods, or even hedges in particular situations; they may by arresting or turning the sluggish currents of saturated air become barriers. It is said that malaria is never found more than 2500 feet above the level of the sea; this may arise either from the lowness of the dew-point, or the absence of that density of steam which exists only in the lower regions of the atmosphere.

The difference observable between the natives of a warm and damp country, and strangers coming to it from a colder climate, in their respective capabilities of resisting malaria is 
striking, but explicable on the supposition that obstruction of the ordinary amount of evaporation is the evil experienced. By the natives, the moisture which cannot find its way out of the body by evaporation, may be thrown off by exudation, while the temperature of the body may be kept down by suitable regimen. But a stranger coming from a cold and dry climate, accustomed to take considerable quantities of heating food into his stomach, and to have much caloric carried off by evaporation, has a sudden stop put to this most important process; the water and fire remain in the system, and fever is the result. Nature deranged in her operations struggles with these new circumstances. The stomach refuses food, because to take it would be heaping new fuel on the body already overcharged with fire. A copious perspiration by exudation sometimes takes place, but mostly when the superabundant fire has been dissipated. Inquiry may possibly show that this is the ordinary expedient of nature under the influence of a heated atmosphere charged with an excess of steam. Perhaps as evaporation is checked exudation increases, and with suitable regimen, the system may in time become adapted to the climate. It is observed that the natives of such climates appear to have a clammy moisture on their skins, and their complexions are sallow. The black race are the least affected by a hot and damp atmosphere; does exudation with them supply the place of evaporation in a greater degree than among the European races?

If the foregoing observations be well founded, it may be presumed that in those parts of the world which have a high temperature malaria will be found, and especially when the air has been some time stagnant, in the following situations, viz.

1. Over the open sea. It will be mild here because the temperature is not very high.

2. Over slowly moving rivers. They will be somewhat more heated by the sun than the sea is, and will therefore evaporate more freely.

3. Over meadows and woods. The great extent of moist surfaces admits of great evaporation from these.

4. Over shallow stagnant water. The temperature of the water will be high, and evaporation consequently great.

5. Over tide sands and muds. These become very hot, and consequently evaporate copiously.

6. Over marshes. These combine great heat, extensive surface for evaporation, and abundant moisture.

With due attention to local influences I would then propose, in order to ascertain whether malaria be or be not the effect 
of an excess of steam in the atmosphere, to have registers kept of the thermometrical, hygrometrical, and barometrical states of the air wherever malaria as found to prevail. It would be also more satisfactory if the force and direction of the wind were noted. Such registers may possibly exist at present, but so little attention has been paid to hygrometry, as to make it unlikely that any should be found that would be satisfactory in the detail. The object of the greatest importance is to ascertain the dew-point, that being the point at, which evaporation ceases from substances of equal temperature, and from this to any higher temperature is to be deduced the energy of evaporation. Possessed of registers of this description, it would be possible to exhibit scales of the drying powers of the air at all temperatures that are found most conducive to health. Physicians might then be enabled to direct patients to remove to a more moist, or to a dryer atmosphere, as particular cases might require.- New modes of prevention and cure might also be devised, such as exposing the patients to strong currents of air, drying the air by heating it, or even by taking the steam out of it by exposure to hot salt, lime, \&c. \&c. Exudation in a steam or hot air bath might be tried as a succedaneum to evaporation. These are however only speculations, and facts are the things wanted. The object of the writer of this paper has been to invite attention to the subject, in order to obtain the facts requisite to the formation of a more conclusive opinion.

Mean monthly Hygrometrical Return for the year 1832, in the Island of St. Vincent, as given in the Official Report.

\begin{tabular}{|c|c|c|c|c|c|c|c|c|c|c|c|}
\hline Jan. & Feb. & Mar. & April. & May. & June. & July. & Aug. & Sept. & Oct. & Nov. & Dec. \\
\hline 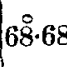 & 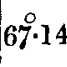 & & & & & 70.95 & 69. & יి & $69^{\circ}$ & 0 & $67 \cdot 31$ \\
\hline
\end{tabular}

A Table of the Deaths per 1000 of Strength, and the portion of those roho died of Fever, per Annum, of the White Troops

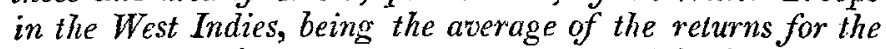
Twenty Years from 1817 to 1836 , arranged in the order of the Mortality. Taken from the Official Report from Troentytwo Stations.

\begin{tabular}{|c|c|c|c|}
\hline & & $\begin{array}{l}\text { Deaths in } \\
1000 .\end{array}$ & $\begin{array}{c}\text { Deaths by } \\
\text { Fever. }\end{array}$ \\
\hline 1. & 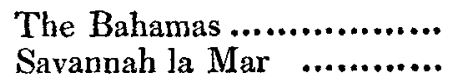 & $\begin{array}{l}200 \\
200\end{array}$ & \\
\hline 3. & Montego Bay .................. & $178-9$ & $150-7$ \\
\hline
\end{tabular}


Prof. Forbes on the Colour of Steam.

\begin{tabular}{|c|c|c|c|}
\hline & & $\begin{array}{l}\text { Deaths in } \\
\text { } 1000 .\end{array}$ & $\begin{array}{l}\text { Deaths by } \\
\text { Fever. }\end{array}$ \\
\hline 4. & Spanish 'Town................... & $162-4$ & $141-1$ \\
\hline 5. & Tobago …..................... & $152-8$ & $104-1$ \\
\hline 6 . & 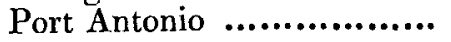 & $149-3$ & $126--0$ \\
\hline 7. & Up Park Camp ................ & $140-6$ & $120-8$ \\
\hline 8. & 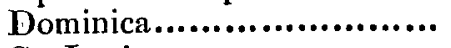 & $137-4$ & $49-3$ \\
\hline 9. & St. Lucia ........................... & $122-8$ & $63-1$ \\
\hline 10. & Port Royal ....................... & $113-1$ & $93-9$ \\
\hline 11 . & Trinidad ........................... & $106-3$ & $61-6$ \\
\hline 12. & Falmouth $\ldots . . . \ldots \ldots \ldots \ldots \ldots \ldots$ & $102-6$ & $80-0$ \\
\hline 13. & Stony Hill $\ldots \ldots \ldots \ldots \ldots \ldots \ldots \ldots$ & $90-2$ & $70-5$ \\
\hline 14. & British Guiana & $84-0$ & $59-2$ \\
\hline 15. & Lucea & $84-9$ & $63-2$ \\
\hline 16. & Fort Augusta $\ldots \ldots \ldots \ldots \ldots \ldots$ & $73-5$ & $55-5$ \\
\hline 17. & St. Kits, Nevis and Tortola & $71-0$ & $42-1$ \\
\hline 18. & Grenada & $61-8$ & $26-3$ \\
\hline 19. & Barbadoes $\quad . . . . . . . . . . . . . . . . .$. & $58-5$ & $11-8$ \\
\hline 20. & St. Vincents...................... & $54-9$ & $11-2$ \\
\hline 21. & Antigua and Montserrat...... & $40-6$ & $14-9$ \\
\hline 22. & Maroon Town & $32-7$ & $15-3$ \\
\hline
\end{tabular}

The most sickly as well as the most fatal period of the year extends from August to December, and during this time the winds are generally from the south and west. The least unhealthy months are March, April, and May, when the tradewind blows from the east. The annual mortality of the troops in England has for a long series of years been only fifteen to the thousand.

XXI. On the Colour of Steam under certain circumstances. By Professor Fonbes *.

N the end of May or beginning of June last, I happened to stand near a locomotive engine on the Greenwich railway, which was discharging a vast quantity of high pressure steam by its safety valve. I chanced to look at the sun through the ascending column of vapour, and was struck by seeing it of a very deep orange red colour, exactly similar to dense smoke, or to the colour imparted to the sun when viewed through a common smoked glass.

I did not pay much attention to the fact at the moment, nor did I attempt to vary the experiment; but reflecting on it af-

* Communicated by the Author. 